\title{
A study on passengers preference towards KSRTC in Thrissur district
}

Swathy V. Chandran

Received : 13.08.2019; Revised : 03.09.2019; Accepted : 17.09.2019

\begin{abstract}
Passenger bus transport nationalization process is only partial in Kerala. The share of KSRTC fleet in the State's total stage carriages is only about one-third as mentioned. These transport undertakings as public enterprises are conceived and organized to function as commercial enterprises engaged in economic activity involving huge outlays of public investment. Social and economic objectives of providing efficient and economical transportation facilities to the masses have been the prime consideration for bringing the passenger road transportation system under the umbrella of the state which was sought to be achieved by the road transport corporation act. The objectives of the study are to identify passenger preference towards KSRTC in Thrissur, analyze the quality of road transport service and to compare the customer preference of customers between KSRTC and other modes of transport. Data was collected from 60 respondents through purposive sampling. The findings was that majority of the passengers prefer KSRTC Majority of the passengers prefer KSRTC due to the low fare given by them and also the passengers are of the opinion that the punctuality of KSRTC buses are to be improved the most. One of the important suggestions was that the KSRTC can provide students concessions and other facilities for increasing the use of these buses by the youngsters. Government can make new routes to improve the reach and also make more income.
\end{abstract}

KEY WORDS : Passenger preference, KSRTC, Quality of service

How to cite this paper : Chandran, Swathy V. (2019). A study on passengers preference towards KSRTC in Thrissur district. Internat. J. Com. \& Bus. Manage, 12(2) : 46-51, DOI: 10.15740/HAS/IJCBM/12.2/46-51. Copyright@ 2019: Hind Agri-Horticultural Society. 